Bibliotecas. Vol 37, №2, julio - diciembre, 2019. EISSN: 1659-3286

URL: http://www.revistas.una.ac.cr/index.php/bibliotecas/index

DOI: http://dx.doi.org/10.15359/rb.37-2.2

Licencia: Creative Commons (BY-NC-SA) 4.0 Internacional

\title{
Investigación y gestión documental en la Facultad de Filosofía y Letras de la Universidad Nacional, Costa Rica: 1973-2015
}

Research and Document Management at the Faculty of Philosophy and Letters of the National University, Costa Rica: 1973-2015

Aracelly Ugalde Víquez

Bibliotecóloga jubilada

\begin{abstract}
Resumen
La celebración del cuadragésimo aniversario de la Facultad de Filosofía y Letras de la Universidad Nacional, Costa Rica, fue un momento oportuno para analizar su aporte a la institución, a la formación de profesionales y a la sociedad costarricense. Este análisis de la investigación y de la creación del conocimiento generado tanto por el personal académico como por la población estudiantil en la Facultad de Filosofía y Letras de la Universidad Nacional, corresponde al año de creación de la Universidad en 1973 hasta el 2015. Los datos utilizados fueron extraídos de las fuentes documentales originales y secundarias localizadas en los archivos y bibliotecas de esa casa de estudios universitarios y los informes de los Trabajos Finales de Graduación (TFG) presentados por el estudiantado de grado y de posgrado.

Así, se muestra el panorama del quehacer histórico y actual de la Facultad, las líneas de investigación, la coordinación entre la investigación realizada por los profesores y la de los estudiantes, también la relación con los planes estratégicos de cada una de las unidades académicas para la gestión de su quehacer y con esta información se pueda deducir el potencial de producción editorial. Se realizaron comparaciones entre los procesos de gestión y se evacuaron dudas actuales que responden a las preguntas: ¿cuáles son las líneas de investigación de la Facultad de Filosofía y Letras?, ¿cuál es la fortaleza disciplinar que caracteriza el pensamiento en esta facultad?, ¿hay relación entre los temas estudiados por estudiantes y los proyectos del personal académico?, ¿quiénes son los autores que se estudiaron? y ¿cuáles son las publicaciones que conforman la memoria documental?
\end{abstract}

\section{Palabras clave}

Gestión documental universitaria; investigación científica; investigación social; investigadores; académicos; estudiantes; líneas de investigación; trabajos finales de graduación, Universidad Nacional, Facultad de Filosofía y Letras. 
Bibliotecas. Vol. 37, № 2, julio - diciembre, 2019. EISSN: 1659-3286

URL: http://www.revistas.una.ac.cr/index.php/bibliotecas/index

\begin{abstract}
The celebration of the 40th anniversary of the Faculty of Philosophy and Letters of the Universidad Nacional, Costa Rica, was an opportune moment to analyze its contribution to the institution, to the training of professionals and to Costa Rican society. This analysis of research and the creation of knowledge generated both by academic staff and by the student population in the Faculty of Philosophy and Letters of the Universidad Nacional, corresponds to the year of creation of the University in 1973 until 2015. The data used were the original and secondary documentary sources located in the archives and libraries of this university and the reports of the Final Works of Graduation (TFG) presented by the undergraduate and graduate students.

Thus, it shows the panorama of the historical and current work of the Faculty, the lines of research, the coordination between the research carried out by the professors and that of the students, as well as the relationship with the strategic plans of each of the academic units for the management of their work and with this information the potential for editorial production can be deduced. With this panorama, comparisons were made between management processes and current doubts were dispelled, such as: what are the research lines of the Faculty of Philosophy and Letters, what is the disciplinary strength that characterizes thinking in this faculty, is there a relationship between the topics studied by students and the projects of academic staff, who are the authors studied, and what are the publications that make up the documentary memory?
\end{abstract}

\title{
Keywords
}

University document management; scientific research; social research; researchers; academics; students; lines of research; final graduation papers, final graduate works, Universidad Nacional, Faculty of Philosophy and Letters.

\section{Antecedentes}

La información académica y la investigación realizada en la universidad debe ser gestionada profesionalmente porque con ella se demuestran los mejores estándares de calidad y excelencia ante la sociedad y el mundo, el cumplimiento de la misión a la que se comprometió ante el pueblo que sostiene su financiamiento y que confía en que la formación de sus jóvenes y futuros profesionales se realiza exitosamente. Además, la información académica es el insumo esencial para lograr una administración eficiente y garantiza que la toma de decisiones se fundamente en evidencia y en bases científicas verificables. Realizar esa gestión de información es una especialidad de la bibliotecología y la documentación, por esa razón se comparte en este artículo la experiencia de gestionar información académica de forma profesional, porque aporta un insumo histórico y un modelo interesante. 
La información producida en la academia es su patrimonio documental y está constituida por los documentos que son el resultado de la investigación realizada en los programas, los proyectos y las actividades académicas, especialmente los artículos, las ponencias y los libros, que tienen sello editorial y los trabajos finales de graduación elaborados por la comunidad estudiantil.

El estudio y la generación de información sobre los aportes de la Facultad de Filosofía y Letras a la Universidad Nacional, a la sociedad costarricense y al mundo son insumos fundamentales para la gestión de la información que se necesita urgentemente en la toma de decisiones para planear el futuro de las carreras que se imparten para adecuarlas a las necesidades costarricenses. La Universidad Nacional, en el 2015, sumó cuarenta y dos años de existencia, al igual que la Facultad y, en ese lapso se ha generado una vasta cantidad de información y de conocimiento que estaba dispersa y no podía ser analizada de forma integral; entre sus datos, el personal académico puede descubrir: áreas de interés y de desinterés, logros, atrasos, desafíos, ideales, entre otros. Es esa información la que se quiere propiciar con este tipo de investigación.

Desde los inicios de la Facultad de Filosofía y Letras en 1973, se han formulado y ejecutado numerosos Programas, Proyectos y Actividades Académicas (PPAA), aunque sobre las actividades realizadas en sus inicios no hay información documental en el archivo institucional, y en cuanto a la producción intelectual con sello editorial de esta facultad son pocos los ejemplares identificados. Por su parte, los Trabajos Finales de Graduación (TFG) también son el resultado de la acción prioritaria de la universidad que es la docencia, por lo cual dichos documentos representan los logros y desafíos de la facultad en relación con la formación que recibió la población graduada en los niveles de licenciatura y posgrado. Ante este panorama, la presente indagación logró identificar 1351 PPAA (del año 1998 hasta el 2015) y 869 TFG (de 1973 hasta el 2015); estos representan un gran esfuerzo intelectual y económico con miras a la producción de nuevo conocimiento. Por esa razón, es tan importante la gestión documental que debe garantizar la calidad académica, el avance científico y el aporte a la educación. 
La Facultad de Filosofía y Letras es parte de la Universidad Nacional, está ubicada en el Campus Omar Dengo en Heredia, Costa Rica. Esta Facultad está integrada por las siguientes unidades académicas, escuelas e institutos, que han impartido y graduado a profesionales en dieciséis titulaciones en el nivel de grado y once en posgrado:

* Escuela de Bibliotecología, Documentación e Información (EBDI): Licenciatura y Bachillerato en Bibliotecología y Documentación con salida lateral de Diplomado, Licenciatura y Bachillerato en Bibliotecología Pedagógica, con salida lateral de Diplomado.

* Escuela Ecuménica de Ciencias de la Religión (EECR): Diplomado en Teología, Bachillerato en Teología, Bachillerato en Enseñanza de la Religión, Licenciatura en Enseñanza de la Religión, Maestría en Estudios Teológicos y Doctorado Interdisciplinario en Letras y Artes en América Central.

* Escuela de Filosofía (EF): Bachillerato en la Enseñanza de la Filosofía, Bachillerato y Licenciatura en Filosofía, Maestría en Bioética y Doctorado en Pensamiento Latinoamericano.

* Instituto de Estudios Latinoamericanos (IDELA): Licenciatura en Estudios Latinoamericanos, Maestría en Estudios Latinoamericanos y Maestría en Derechos Humanos y Educación para la Paz.

* Instituto de Estudios de la Mujer (IEM): Bachillerato en Género y Desarrollo, Maestría Regional en Estudios de la Mujer y Maestría en Violencia Intrafamiliar y de Género.

- Escuela de Literatura y Ciencias del Lenguaje (ELCL): Bachillerato en la Enseñanza del Español, Bachillerato en Literatura y Lingüística con énfasis en Español, Licenciatura en Literatura y Lingüística con énfasis en Español, Bachillerato en Inglés con salida lateral de Diplomado, Bachillerato en la Enseñanza del Inglés, Diplomado y Bachillerato en Enseñanza del Inglés para I y II Ciclo. Diplomado en Lengua Francesa. Bachillerato en Lengua Francesa, Bachillerato en la Enseñanza del Francés, Licenciatura en Lingüística aplicada con énfasis en Francés, Maestría en Traducción y Maestría en Segundas Lenguas y Culturas. 
La misión y la visión de la Facultad de Filosofía y Letras se indican en el Plan Estratégico 20132017 y son las siguientes:

\section{Misión}

La Facultad de Filosofía y Letras es una entidad académica que se dedica a crear, difundir y beneficiarse del conocimiento en los campos de la reflexión filosófica, las manifestaciones socioculturales, la producción simbólica, la comunicación humana y el estado del saber en general. Promueve los enlaces e interrelaciones entre esos conocimientos, con el fin de que la comunidad humana de su entorno histórico alcance etapas superiores de convivencia social y material.

\section{Visión}

La Facultad de Filosofía y Letras se concibe como un centro de actividad y pensamiento académico que sistematiza y promueve un nuevo saber humanístico, desde aproximaciones analíticas y dinamizadoras del campo de las letras, la filosofía, el lenguaje y la cultura. De manera flexible, pertinente e innovadora, busca contribuir a la promoción de la equidad, la justicia, el reconocimiento de las diversidades y la construcción de una cultura basada en la libre y solidaria convivencia.

Se han delimitado cuatro áreas estratégicas en la Facultad de Filosofía y Letras: educación para la promoción humana y el desarrollo social, culturas e identidades, desarrollo y tendencias en las sociedades contemporáneas, y tecnologías de la información y la comunicación. Estas áreas contemplan de manera general las áreas de interés específicas de cada una de las unidades que integran la Facultad, vistas como un marco amplio que permite desarrollar acciones de articulación entre las distintas academias, con otras instancias de la Universidad y con organismos nacionales e internacionales con los que se comparten intereses, áreas temáticas y valores. En el Cuadro 1 se muestran las áreas generales y específicas por unidad académica. 


\section{Cuadro 1}

Vinculación de las áreas estratégicas de Facultad de Filosofía y Letras con las áreas estratégicas de las unidades académicas

\begin{tabular}{|c|c|c|c|c|}
\hline $\begin{array}{c}\text { Áreas } \\
\text { estratégicas de la } \\
\text { UNA }\end{array}$ & $\begin{array}{c}\text { Educación y } \\
\text { desarrollo integral }\end{array}$ & $\begin{array}{c}\text { Humanismo, arte } \\
\text { y cultura }\end{array}$ & $\begin{array}{l}\text { Sociedad y } \\
\text { desarrollo } \\
\text { humano }\end{array}$ & $\begin{array}{c}\text { Tecnologías de la } \\
\text { Información y } \\
\text { Comunicación }\end{array}$ \\
\hline $\begin{array}{c}\text { Áreas de la } \\
\text { Facultad de } \\
\text { Filosofía y Letras } \\
\text { y de las Unidades } \\
\text { Académicas } \\
\end{array}$ & $\begin{array}{c}\text { Educación para la } \\
\text { promoción } \\
\text { humana y } \\
\text { desarrollo social }\end{array}$ & $\begin{array}{l}\text { Culturas e } \\
\text { identidades }\end{array}$ & $\begin{array}{c}\text { Desarrollo y } \\
\text { tendencias en las } \\
\text { sociedades } \\
\text { contemporáneas }\end{array}$ & $\begin{array}{l}\text { Tecnologías de la } \\
\text { Información y } \\
\text { Comunicación }\end{array}$ \\
\hline $\begin{array}{c}\text { Escuela de } \\
\text { Filosofía }\end{array}$ & $\begin{array}{c}\text { Lógica y } \\
\text { epistemología } \\
\text { Metafísica } \\
\text { Ética } \\
\text { Estética }\end{array}$ & $\begin{array}{c}\text { Historia del } \\
\text { pensamiento } \\
\text { Filosofía } \\
\text { latinoamericana } \\
\text { Filosofías del } \\
\text { mundo }\end{array}$ & $\begin{array}{c}\text { Filosofía política y } \\
\text { social } \\
\text { Bioética }\end{array}$ & $\begin{array}{l}\text { Impacto cultural y } \\
\text { social de las } \\
\text { nuevas } \\
\text { tecnologías de la } \\
\text { comunicación }\end{array}$ \\
\hline $\begin{array}{l}\text { Escuela de } \\
\text { Bibliotecología, } \\
\text { Documentación e } \\
\text { Información }\end{array}$ & $\begin{array}{c}\text { Bibliotecología en } \\
\text { la mediación } \\
\text { pedagógica }\end{array}$ & $\begin{array}{c}\text { Cultura } \\
\text { informacional } \\
\text { Conservación } \\
\text { documental }\end{array}$ & $\begin{array}{c}\text { Gestión de } \\
\text { unidades de } \\
\text { información } \\
\text { documental } \\
\text { Investigación en } \\
\text { bibliotecología }\end{array}$ & $\begin{array}{l}\text { Tecnologías de la } \\
\text { información y de } \\
\text { la comunicación } \\
\text { en bibliotecología }\end{array}$ \\
\hline $\begin{array}{c}\text { Escuela de } \\
\text { Ecuménicas y } \\
\text { Ciencas de la } \\
\text { Religión }\end{array}$ & $\begin{array}{l}\text { Epistemología y } \\
\text { metodologías } \\
\text { para el estudios } \\
\text { de las religiones y } \\
\text { teologías }\end{array}$ & $\begin{array}{c}\text { Textos y } \\
\text { textualidades } \\
\text { religiosas } \\
\text { Espiritualidades }\end{array}$ & $\begin{array}{l}\text { Prácticas } \\
\text { religiosas } \\
\text { Estructuras } \\
\text { religiosas }\end{array}$ & \\
\hline $\begin{array}{c}\text { Instituto de } \\
\text { Estudios de la } \\
\text { Mujer }\end{array}$ & $\begin{array}{c}\text { Estudios de la } \\
\text { mujer y género } \\
\text { Derechos } \\
\text { humanos de las } \\
\text { mujeres } \\
\text { lgualdad y } \\
\text { equidad de } \\
\text { género } \\
\text { Género y } \\
\text { comunicación } \\
\text { Género, } \\
\text { educación e } \\
\text { inclusión social }\end{array}$ & $\begin{array}{c}\text { Género y } \\
\text { diversidades } \\
\text { Violencia contra } \\
\text { las mujeres y } \\
\text { violencia de } \\
\text { género }\end{array}$ & $\begin{array}{l}\text { Historia de las } \\
\text { mujeres } \\
\text { Género, } \\
\text { desarrollo y } \\
\text { nuevas } \\
\text { perspectivas }\end{array}$ & \\
\hline
\end{tabular}




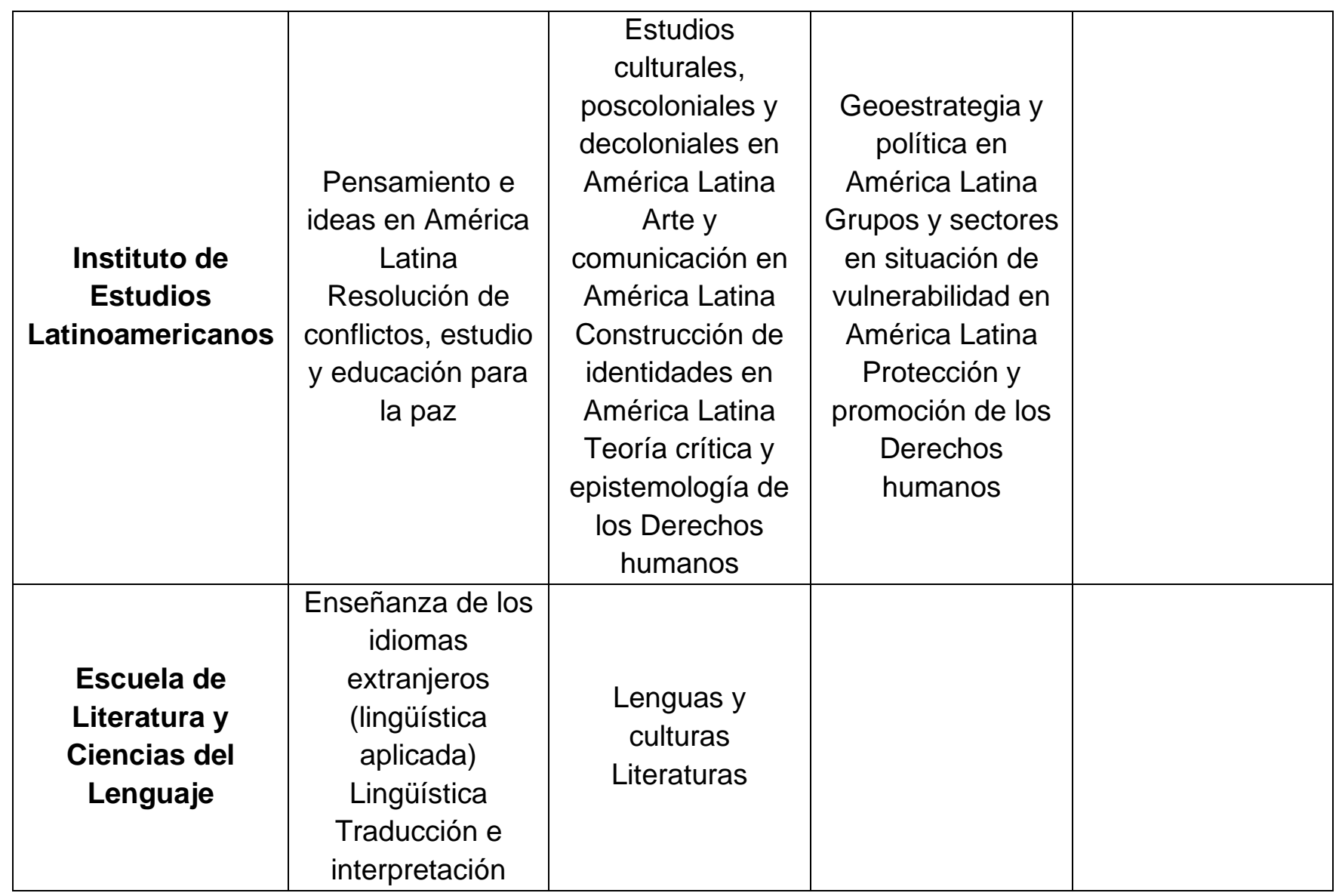

Fuente: Plan estratégico de la Facultad de Filosofía y Letras (2013)

\section{Objeto de estudio}

El objeto de estudio de esta investigación está constituido por la documentación elaborada por los académicos investigadores que participaron en 1351 programas, proyectos y actividades académicas, desde 1998 hasta el 2015, y también por los informes del estudiantado a partir de los 869 trabajos finales de graduación en el periodo 1973-2015. 


\section{Objetivos}

1. Analizar la producción documental de los estudiantes de la Facultad de Filosofía y Letras de la Universidad Nacional, por medio de los Trabajos Finales de Graduación presentados desde 1973 al 2015.

2. Analizar los Programas, Proyectos y Actividades Académicas realizados en la Facultad de Filosofía y Letras desde 1998 hasta el 2015.

3. Identificar la producción académica de la Facultad de Filosofía y Letras de 1973 al 2015 a partir de los objetivos anteriores, con el fin de elaborar un catálogo de producción académica de la Facultad.

\section{Metodología}

La metodología utilizada en esta investigación tuvo un enfoque mixto y fue desarrollada por etapas. La primera fue cuantitativa y se aplicaron métodos de tipo descriptivo, que consistieron en identificar, describir, caracterizar y relacionar las fuentes de información sobre la producción intelectual entre sí. La segunda etapa fue cualitativa y consistió en el análisis de la información recolectada, por medio de la lectura de los TFG, con el fin de caracterizarla, establecer relaciones e identificar temáticas similares.

Para analizar los informes de los TFG de los estudiantes en los últimos cuarenta y dos años, desde 1973 al 2015, en primer lugar, fue necesario identificarlos revisando las actas de graduación de todas las carreras a lo largo de la historia y documentos administrativos, además, debido a que muchos de estos informes no se encontraban en las bibliotecas universitarias, se tuvo que localizarlos en los archivos institucionales, en los catálogos en línea de las bibliotecas costarricenses, especialmente en el Sistema de información Documental de la Universidad Nacional (SIDUNA), en los catálogos de las editoriales y en los catálogos impresos publicados anualmente en el Decanato de la Facultad de Filosofía y Letras. 
A pesar de que se realizó una búsqueda exhaustiva, que incluyó también el Archivo de la Facultad, en este solo se conservaron los informes y las actas de reuniones, por lo que en algunos casos no fue posible encontrar documentos con los productos finales resultado de estas investigaciones. En otros casos se seleccionaron proyectos por su importancia histórica y fue necesario buscar a las personas postulantes y solicitarles su propia copia impresa, estos documentos fueron solicitados en calidad de préstamo, duplicados, escaneados para su conservación y editados junto con el autor y se publicaron en la Biblioteca Electrónica Scriptorium. Además, con los datos identificados y los documentos originales se procedió a hacer la catalogación e ingresarlos en una base de datos que además incluía un resumen de cada material documental a texto completo, utilizando el programa de la Unesco Winisis; asimismo, se inició el proceso de digitalización y edición para ofrecerlos a texto completo. Posteriormente, esa información se analizó por unidad académica.

Paralelamente, se realizó el mismo tipo de procedimiento con respecto a los PPAA, libros con y sin sello editorial, artículos y revistas. También, la información reunida fue ordenada y se procedió a ingresarla en tres bases de datos según su naturaleza. Se realizó un arduo trabajo de recuperación de información dispersa y la digitalización de la que estaba en formato impreso para ofrecerla a texto completo. Luego, se logró revisar cualitativamente uno por uno todos los documentos de los 1351 PPAA localizados y, mediante la lectura, revisión y el análisis correlativo, se determinaron sus características y las líneas de investigación. Por último, con todos esos datos reunidos se obtuvieron las características de la investigación mediante el uso del programa Excel; con los datos tabulados, se elaboraron tablas y cuadros sobre sus especificidades y son los resultados del análisis los que se presentan en este documento.

Los datos referenciales se publicaron en siete catálogos impresos y en línea, que se pueden acceder por medio del Repositorio Institucional de la Universidad, esos documentos son: un catálogo sobre los cuarenta años de trabajos finales de graduación, todos los catálogos anuales de los proyectos académicos y dos sobre la producción documental con sello editorial. Se reconoce la labor de las autoridades que asumieron la responsabilidad de dirigir esta Facultad, especialmente las vicedecanas que durante 20 años fueron profesoras de la Escuela de 
Bibliotecología, Documentación e Información y de la Escuela de Literatura y Ciencias del Lenguaje, que elaboraron catálogos referenciales de forma anual, estos facilitaron la identificación de la información y fueron insumos que garantizaron el respaldo, el ordenamiento y la conservación de mucha información sobre el quehacer académico de la Facultad. Además, las profesionales Jorleny Valerio Villalobos y Yenory Rodríguez Matamoros colaboraron en la recolección, catalogación y revisión de la información sobre los TFG y también participaron en la elaboración de dos catálogos que se publicaron con datos resultantes de esta investigación.

Sin embargo, se aclara que, a pesar de esos 20 años en los que se generaron acciones para ordenar y facilitar la información producida en la facultad, en cada administración se cambiaron los formatos y los elementos descriptivos, por lo que fue necesario sistematizarlos. Además, faltaban 20 años de trabajo descriptivo y documental y los primeros años del origen de la Facultad, que no tenía respaldo de los proyectos en el archivo. De acuerdo con lo anterior, se presentan los resultados de esta investigación en dos secciones o fases, la primera se refiere a los TFG y la segunda presenta el análisis de los PPAA.

\section{Resultados}

a. Fase 1: Análisis de los Trabajos Finales de Graduación de 1973 al 2015

Las primeras siete tesis de la Facultad de Filosofía y Letras corresponden a 1975 y fueron elaboradas por estudiantes de licenciatura del Instituto de Estudios Latinoamericanos (IDELA) y que se muestran en el Cuadro 2. A pesar de este rápido inicio, es poca la cantidad de trabajos finales de graduación presentados en estos 40 años, los cuales suman 869. Este es un resultado que llama la atención, así como la distribución de estos entre el grado de licenciatura que corresponde a 435 y el posgrado con 434 , cifra muy similar, otro hallazgo interesante y que también demuestra un problema de atraso o más bien una limitación en relación con la cantidad de estudiantes que ingresan todos los años. El Cuadro 3 detalla con mayor especificidad la información. 


\section{Cuadro 2}

Primeras tesis de la Facultad de Filosofía y Letras del IDELA, de la Universidad Nacional, 1975

\begin{tabular}{|l|l|}
\hline \multicolumn{1}{|c|}{ Postulantes } & \multicolumn{1}{c|}{ Título } \\
\hline Castillo Esquivel, Nury & $\begin{array}{l}\text { Determinismo ambiental y posibilismo en la Vorágine de José } \\
\text { Eustasio Rivera }\end{array}$ \\
\hline Chacón Gutiérrez, Albino & El nivel narrativo en "Hijo de Hombre" de Augusto Roa Bastos \\
\hline $\begin{array}{l}\text { Cubillo de Hernández, María de } \\
\text { los Ángeles }\end{array}$ & $\begin{array}{l}\text { Raza de bronce" de Alcides Arguedas; novela de } \\
\text { explotadores y explotados }\end{array}$ \\
\hline $\begin{array}{l}\text { Ramírez Meléndez, Carmen } \\
\text { Eugenia }\end{array}$ & $\begin{array}{l}\text { El sistema cooperativista como posible solución al problema } \\
\text { de la tenencia de la tierra en Costa Rica; estudio de caso en } \\
\text { la cooperativa de Caficultores Libertad R.L. }\end{array}$ \\
\hline $\begin{array}{l}\text { Rodríguez Quesada, José } \\
\text { Roberto }\end{array}$ & $\begin{array}{l}\text { La integración y su importancia en el desarrollo cooperativo } \\
\text { de ahorro y crédito }\end{array}$ \\
\hline Segura de Chavarría, Marielos & A propósito de Don Segundo Sombra \\
\hline Valverde Abarca, Efraín & $\begin{array}{l}\text { Doña Bárbara de Rómulo Gallegos: versión literaria de una } \\
\text { realidad histórica }\end{array}$ \\
\hline
\end{tabular}

Fuente: propia de la autora (2018).

\section{Cuadro 3}

Cantidad de población graduada en los trabajos finales de graduación de la Facultad de Filosofía y Letras de la Universidad Nacional en el periodo 1973-2015

Fuente: propia de la autora (2018).

\begin{tabular}{|l|c|c|}
\hline \multicolumn{1}{|c|}{ Grado } & Cantidad & Porcentaje \\
\hline Licenciatura & 435 & 50 \\
\hline Maestría & 389 & 45 \\
\hline Doctorado & 45 & 5 \\
\hline Total & $\mathbf{8 6 9}$ & $\mathbf{1 0 0}$ \\
\hline
\end{tabular}

También, se identificó una tesis que hereda la Escuela de Literatura y Ciencias del Lenguaje, de 1972 proveniente de la Escuela Normal Superior (Ver Imagen1). 


\section{Imagen 1 \\ Imagen escaneada de tesis de la Escuela Normal Superior, 1972}

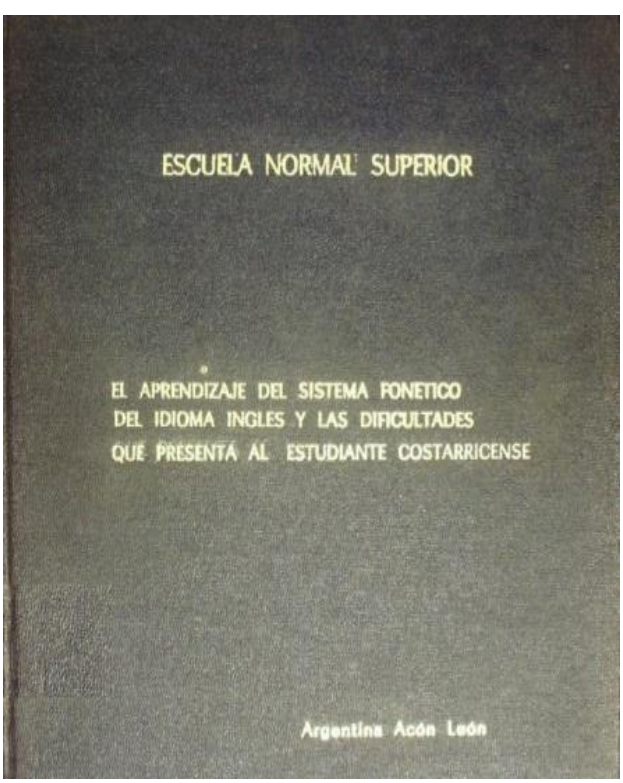

Fuente: propia de la autora (2018).

\section{i. Áreas temáticas más representativas en los TFG}

Existe una amplia variedad de áreas, problemas y temas de investigación con una cantidad considerable de trabajos realizados y con gran dispersión. Los temas más estudiados en la Facultad provienen de la Escuela de Literatura y Ciencias del Lenguaje: literatura, traducción, lingüística, análisis y crítica literaria; además, un número importante estudian asuntos relacionados con los derechos (sobre todo derechos humanos) y sobre la mujer y, llama la atención, que hay 150 TFG que tratan áreas temáticas relacionadas con educación, enseñanza y aprendizaje.

Esta cantidad de investigaciones en temáticas similares facilita que se realicen nuevas investigaciones sobre el conocimiento que se ha producido en la Facultad en esas áreas y podrían constituirse en nuevos objetos de estudio. En el Cuadro 4 se muestran, a nivel general, las áreas más estudiadas: 


\section{Cuadro 4}

Áreas temáticas más recurrentes de los trabajos finales de graduación de la Facultad de Filosofía y Letras, 1973-2015

\begin{tabular}{|l|c|}
\hline \multicolumn{1}{|c|}{ Temática } & Cantidad \\
\hline Literatura & 324 \\
\hline Traducción & 230 \\
\hline Lingüística & 153 \\
\hline Derecho & 100 \\
\hline Mujeres & 99 \\
\hline Enseñanza & 98 \\
\hline Análisis y crítica literaria & 95 \\
\hline Inglés & 74 \\
\hline Novela & 63 \\
\hline Género, sexo & 57 \\
\hline Teología & 53 \\
\hline Iglesia & 41 \\
\hline Educación & 37 \\
\hline Escritores & 33 \\
\hline Historia & 31 \\
\hline Cultura & 30 \\
\hline Bibliotecas & 26 \\
\hline Lenguaje & 26 \\
\hline Ética & 26 \\
\hline Bioética & 23 \\
\hline Adquisición de segundo lenguaje & 21 \\
\hline Violencia intrafamiliar & 19 \\
\hline Feminismo & 18 \\
\hline Métodos de enseñanza & 17 \\
\hline Traductores & 17 \\
\hline Salud & 16 \\
\hline Aprendizaje & 15 \\
\hline Análisis del discurso & 15 \\
\hline Español & 14 \\
\hline Niños & 14 \\
\hline Cuentos & 14 \\
\hline Religión & \\
\hline Aspectos jurídicos & 14 \\
\hline & \\
\hline
\end{tabular}


Fuente: propia de la autora (2018).

\begin{tabular}{|l|l|}
\hline Aspectos sociales & 14 \\
\hline Francés & 14 \\
\hline Gramática & 13 \\
\hline Novela costarricense & 13 \\
\hline
\end{tabular}

En el cuadro se aprecian las áreas de investigación más recurrentes en la Facultad, una gama muy amplia que revela los intereses del estudiantado y el fuerte de la investigación. Llama la atención la importancia que se da a la educación, la enseñanza y el aprendizaje, aunque hay muchos temas relacionados con la cultura y las identidades, así como con el desarrollo y las tendencias en las sociedades contemporáneas.

Interesante destacar que no aparecen temas sobre tecnología, sistemas de información, documentación y comunicación, áreas que son características e históricas desde los orígenes de esta Facultad. Por tanto, hay que fortalecer líneas de investigación que reflejen los intereses de la Facultad, es recomendable sugerir temas al estudiantado que permitan cubrir ampliamente todas las áreas estratégicas para la sociedad costarricense.

Las áreas de investigación en el nivel micro, o sea en el ámbito específico de las unidades académicas, también se pueden determinar y a continuación se aprecian los siguientes resultados.

- Escuela de Bibliotecología, Documentación e Información

En esta escuela se han presentado 65 TFG en la carrera de Licenciatura en Bibliotecología y Documentación, algunos de los cuales están disponibles en formato digital en la página de la Escuela. El primer TFG se presentó en 1994 y cuatro años después el segundo. Los temas más estudiados son los relacionados con las bibliotecas, su creación y gestión; luego, se ha trabajado mucho el tema control bibliográfico y documental (mapeando los siguientes lugares de Costa Rica: Puriscal, San Joaquín, San Rafael, Golfo de Nicoya, Heredia Centro, San Ramón, Cartago y Barva). Otro tema muy estudiado es la evaluación, tanto de servicios, de 
colecciones como de la propia Escuela de Bibliotecología, que ha sido objeto de estudio para analizar su historia y para auditar la calidad de la educación ofrecida al estudiantado. En el Cuadro 5 se presentan los temas estudiados.

\section{Cuadro 5}

\section{Áreas temáticas de los trabajos finales de graduación de la Escuela de Bibliotecología, Documentación e Información, 1973-2015}

\begin{tabular}{|l|c|}
\hline \multicolumn{1}{|c|}{ Temáticas } & Cantidad \\
\hline $\begin{array}{l}\text { Bibliotecas (públicas, infantiles, virtuales, especializadas, } \\
\text { escolares, centros de documentación) }\end{array}$ & 26 \\
\hline Control bibliográfico y documental & 10 \\
\hline Evaluación de colecciones & 5 \\
\hline $\begin{array}{l}\text { Escuela de Bibliotecología, Documentación e Información / } \\
\text { Carrera }\end{array}$ & 3 \\
\hline Auditoría / Control de calidad & 3 \\
\hline Repositorios & 3 \\
\hline Catálogos & 3 \\
\hline Bibliotecólogos & 2 \\
\hline Internet & 2 \\
\hline Lectura & 2 \\
\hline Bases de datos & 1 \\
\hline Orientación a los usuarios & 1 \\
\hline Conservación de documentos & 1 \\
\hline Archivo Nacional & 1 \\
\hline Libros antiguos & 1 \\
\hline Alfabetización & \\
\hline
\end{tabular}

Fuente: propia de la autora (2018).

Con excepción del control documental y la gestión de información, los otros temas que han investigado los estudiantes ya no aparecen específicamente en las áreas estratégicas actuales de la Escuela de Bibliotecología, Documentación e Información, establecidas en el plan estratégico. 
- Escuela Ecuménica de Ciencias de la Religión

En esta unidad académica se han aprobado 74 trabajos finales de graduación con 78 estudiantes graduados. El primero se presentó en 1976 y las líneas más estudiadas son: la teología, la Iglesia Católica, la historia, el catolicismo, el cristianismo, las mujeres y la educación (ver Cuadro 6). En esta escuela hay más coincidencias entre los temas estudiados y los temas propuestos en el plan estratégico.

\section{Cuadro 6}

Áreas temáticas de los trabajos finales de graduación de la Escuela Ecuménica de Ciencias de la Religión, 1973-2015

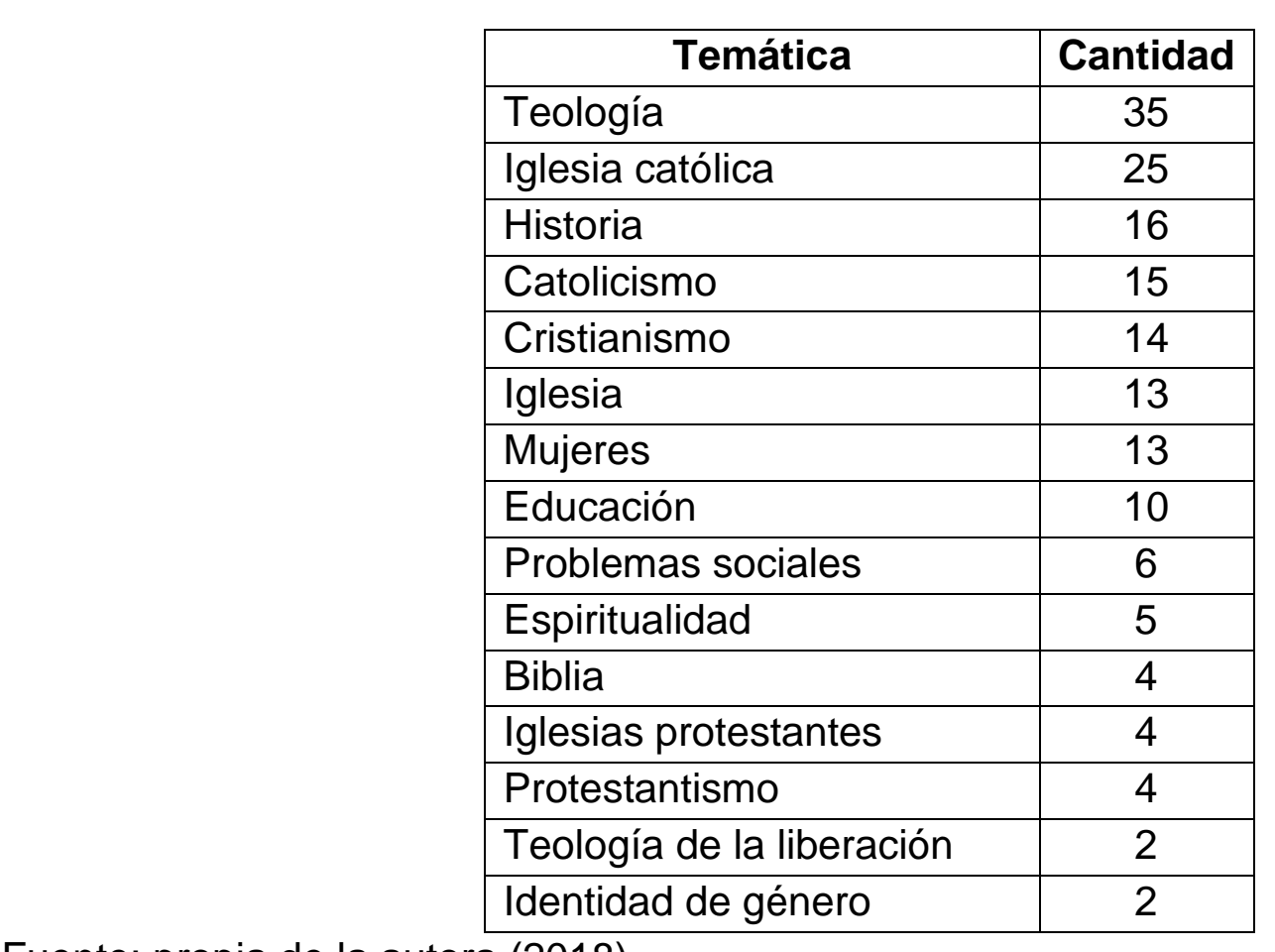

Fuente: propia de la autora (2018).

- Escuela de Literatura y Ciencias del Lenguaje

El primer trabajo final de graduación de la Facultad se presentó en esta Escuela, como se mencionó anteriormente está fechado en 1972 y fue heredado de la Escuela Normal. Es la 
unidad académica con más cantidad de TFG en la Facultad: un total de 393 y 448 graduados. Los temas investigados por nivel general coinciden con los propuestos en el plan estratégico 2013-2017. Los temas más representativos se exponen en el Cuadro 7.

\section{Cuadro 7}

Áreas temáticas más recurrentes de los trabajos finales de graduación de la Escuela de Literatura y Ciencias del Lenguaje, 1973-2015

\begin{tabular}{|l|c|}
\hline \multicolumn{1}{|c|}{ Temáticas } & Cantidad \\
\hline Literatura & 324 \\
\hline Traducción & 230 \\
\hline Lingüística & 153 \\
\hline Inglés & 66 \\
\hline Análisis y crítica literaria & 60 \\
\hline Enseñanza de idiomas & 53 \\
\hline Literatura costarricense & 34 \\
\hline Crítica literaria & 20 \\
\hline Cultura & 18 \\
\hline Traductores & 17 \\
\hline Adquisición de segundo lenguaje & 16 \\
\hline Español & 16 \\
\hline Métodos de enseñanza & 15 \\
\hline Aprendizaje & 14 \\
\hline Gramática & 13 \\
\hline Novela costarricense & 13 \\
\hline
\end{tabular}

Fuente: propia de la autora (2018).

En las carreras de Licenciatura en Lingüística aplicada con énfasis en Francés, Maestría en Traducción y Maestría en Segundas Lenguas y Culturas, la diversidad de temas estudiados es 
tan grande que no se incluye un estudio particular por la dificultad que existe para agrupar las áreas.

En la carrera de Licenciatura en Literatura y Lingüística con énfasis en español destacan el análisis literario y el análisis del discurso, la literatura, la literatura costarricense (especialmente novela, cuentos y poesía), así como la estadounidense, nicaragüense y latinoamericana. Además, lingüística, crítica literaria, gramática, cultura y escritores costarricenses.

Los autores más estudiados, con dos o más TFG son: Joaquín Gutiérrez Mangel, con cuatro, Jorge Debravo con tres, Alejo Carpentier, Ana Cristina Rossi Lara, Carlos Gagini Chavarría, Carlos Luis Fallas Sibaja, Carlos Salazar Herrera, Carmen Lyra, Carmen Naranja Coto, David Herbert Lawrence, Fabián Dobles, Gioconda Belli, Magón, Manlio Argueta Cañas, Ricardo Guiraldes, Rubén Darío, Samuel Rovinski, todos ellos con al menos dos TFG. Los otros autores estudiados con un solo TFG se presentan en el Anexo 1.

- Escuela de Filosofía

La Escuela de Filosofía inició funciones como Departamento en 1973, en 1997 inició el Doctorado en Estudios Latinoamericanos, en el 2006 se constituye en Escuela y en el 2007 se da la apertura de la Licenciatura.

El primer TFG de la Escuela de Filosofía corresponde al 2002 y se presenta en el Doctorado en Estudios Latinoamericanos. Hasta el 2013 se habían presentado 64 trabajos finales de graduación, de los cuales 10 son de licenciatura, 24 de Maestría en Bioética y 30 de doctorado. En relación con las temáticas, estas son diversas, siendo las más representativas la bioética, la ética, los derechos humanos y aspectos jurídicos y la salud, los cuales se resumen de manera precisa en el Cuadro 9. De estos resultados, solo dos coinciden con lo propuesto en el plan estratégico, por lo que se puede sugerir al estudiantado que investigue sobre otros temas, como: lógica y epistemología, metafísica, estética, historia del pensamiento, filosofía latinoamericana 
y del mundo, filosofía política y social, impacto social y cultural de las nuevas tecnologías de comunicación.

\section{Cuadro 9}

Áreas temáticas de los trabajos finales de graduación de la Escuela de Filosofía, 19732015

\begin{tabular}{|l|c|}
\hline \multicolumn{1}{|c|}{ Temáticas } & Cantidad \\
\hline Bioética & 23 \\
\hline Ética & 21 \\
\hline Derechos humanos & 13 \\
\hline Aspectos jurídicos & 12 \\
\hline Salud y salud pública & 11 \\
\hline Investigaciones & 8 \\
\hline Mercado & 5 \\
\hline Pensamiento & 5 \\
\hline Genética humana & 4 \\
\hline Identidad cultural & 4 \\
\hline Aspectos sociales & 3 \\
\hline Escuela de Filosofía & 3 \\
\hline Ética animal & 3 \\
\hline Historia política & 3 \\
\hline Identidad & 3 \\
\hline Moral & 3 \\
\hline Mujeres & 3 \\
\hline Filosofía & 1 \\
\hline
\end{tabular}

Fuente: propia de la autora (2018).

- Instituto de Estudios de la Mujer (IEM)

En la Maestría en Estudios de la Mujer se elaboraron 52 trabajos finales de graduación y los temas estudiados fueron: la participación de las mujeres en la política, mujeres trabajadoras, relaciones de poder y sexualidad femenina; otros temas investigados se muestran en el Cuadro 10. 


\section{Cuadro 10 \\ Áreas temáticas de los trabajos finales de graduación del Instituto de Estudios de la Mujer (IEM), 1973-2015}

\begin{tabular}{|l|c|}
\hline \multicolumn{1}{|c|}{ Temáticas } & Cantidad \\
\hline Participación política de las mujeres & 7 \\
\hline Trabajadoras & 4 \\
\hline Relaciones de poder & 4 \\
\hline Sexualidad femenina & 4 \\
\hline Acoso sexual & 3 \\
\hline Género & 3 \\
\hline Lesbianismo & 3 \\
\hline Violencia contra las mujeres & 4 \\
\hline Participación social & 2 \\
\hline Igualdad de oportunidades & 2 \\
\hline Niñez & 2 \\
\hline Adolescentes & 2 \\
\hline Menopausia & 1 \\
\hline Maternidad & 1 \\
\hline Derechos de las mujeres & 1 \\
\hline Sexismo & 1 \\
\hline Iglesia protestante & 1 \\
\hline Comunicación y género & 1 \\
\hline Mujeres en la historia & 1 \\
\hline Salud mental & 1 \\
\hline Masculinidad & 1 \\
\hline Aborto & 1 \\
\hline Mujeres en el arte & 1 \\
\hline Cáncer de cérvix & 1 \\
\hline
\end{tabular}

Fuente: propia de la autora (2018).

En la Maestría en Violencia Intrafamiliar y de Género se elaboraron 24 TFG y el tema predominante fue la violencia, tal como su nombre lo indica. El Cuadro 11 muestra otros temas estudiados. 


\section{Cuadro 11 \\ Temáticas de los trabajos finales de graduación de la Maestría en Violencia Intrafamiliar y de Género, 1973-2015}

Fuente: propia de la autora (2018).

\begin{tabular}{|l|c|}
\hline \multicolumn{1}{|c|}{ Temáticas } & Cantidad \\
\hline Violencia intrafamiliar & 9 \\
\hline Violencia de género & 7 \\
\hline Violencia infantil & 2 \\
\hline Trata de mujeres & 1 \\
\hline Refugiadas & 1 \\
\hline Violencia contra las mujeres & 1 \\
\hline Estereotipos & 1 \\
\hline Género & 1 \\
\hline Igualdad de oportunidades & 1 \\
\hline
\end{tabular}

Como puede notarse, hay una discordancia entre temas elegidos y temas propuestos en el plan estratégico de la Facultad. Sin embargo, debido a que ambos posgrados eran compartidos con la Universidad de Costa Rica y se cerraron en el 2013, y a que faltan muchos temas por ser abordados desde los TFG, conviene que se retomen en los planes de estudio vigentes en el IEM y como temas de trabajos de graduación del estudiantado, por ejemplo: derechos humanos de las mujeres; igualdad y equidad de género; género y comunicación; género, educación e inclusión social; género y diversidades; historia de las mujeres y desarrollo y nuevas perspectivas.

- Instituto de Estudios Latinoamericanos (IDELA)

Desde sus orígenes, este instituto se destacó por impartir docencia desde un carácter interdisciplinario y multidisciplinario, con académicos de una formación amplia y diversa en las ramas de antropología, historia, literatura, sociología y filosofía; recibiendo en la formación inicial a estudiantes procedentes de diferentes ámbitos como ciencias sociales, letras, humanidades y educación. 
Hasta 2013 se han graduado en el IDELA 197 estudiantes con un total de 159 TFG. El plan de estudios de licenciatura estuvo vigente desde 1974, con reformas en 1980 y 1999; tiene a su haber 58 TFG y 73 graduados. Además, se imparten dos posgrados: la Maestría en Derechos Humanos y Educación para la Paz, que ha titulado a 74 estudiantes con un total de 69 TFG y la Maestría en Estudios Latinoamericanos con énfasis en Cultura y Desarrollo, que ha titulado a 50 máster con 32 TFG. Las áreas temáticas estudiadas son tan variadas que se citan los primeros y últimos títulos en cada maestría para que juzguen:

- Vida de mujeres nicaragüenses en Costa Rica: estudio de casos en Guararí de Heredia 2008.

- Alternativas educativas y jurídicas por y para los pueblos indígenas de Latinoamérica: propuestas decoloniales.

- Moralismos y realidades, una aproximación al tema de la violencia intrafamiliar en Costa Rica, entre los siglos XIX y XX.

- El derecho humano a la libertad de culto y religión en Costa Rica.

- La red de mujeres migrantes nicaragüenses en Costa Rica: de la vulnerabilidad hacia la construcción de derechos humanos para las mujeres, niños y niñas.

Como se mencionó antes, las primeras siete tesis de la Facultad de Filosofía y Letras, que corresponden a 1975, fueron elaboradas por estudiantes de licenciatura del IDELA, la mayoría (5) fueron sobre literatura latinoamericana. En estos 42 años transcurridos (1973-2015), se puede afirmar que hay líneas temáticas de investigación, especialmente sobre la realidad predominante, las identidades culturales populares, la política en América Latina, la región centroamericana y sobre Costa Rica, priorizando en grupos sociales vulnerables, que son muchos. En los Cuadros 12, 13 y 14 se muestran los temas estudiados en la licenciatura y en las maestrías del IDELA. 


\section{Cuadro 12 \\ Áreas temáticas más representativas en los trabajos finales de graduación de la Licenciatura en Estudios Latinoamericanos, 1973-2015}

\begin{tabular}{|l|c|}
\hline \multicolumn{1}{|c|}{ Temáticas } & Cantidad \\
\hline Mujeres & 12 \\
\hline Novela & 8 \\
\hline Política & 8 \\
\hline Literatura & 7 \\
\hline Análisis literario & 5 \\
\hline Indígenas & 4 \\
\hline Educación & 3 \\
\hline Iglesia & 3 \\
\hline Nicaragua & 3 \\
\hline Protestantismo & 3 \\
\hline Refugiados nicaragüenses & 3 \\
\hline Adolescentes & 2 \\
\hline Bienes inmuebles & 2 \\
\hline Campesinado & 2 \\
\hline Condiciones económicas & 2 \\
\hline Cooperativismo & 2 \\
\hline Cristianismo & 2 \\
\hline Cristianos & 2 \\
\hline Crítica literaria & 2 \\
\hline Delitos sexuales & 2 \\
\hline Diplomáticas & 2 \\
\hline Doña Bárbara & 2 \\
\hline Escritoras costarricenses & 2 \\
\hline Escritores bolivianos & 2 \\
\hline Estudios sociales & 2 \\
\hline Historia & 2 \\
\hline Industria & 2 \\
\hline Legislación & 2 \\
\hline Literatura costarricense & 2 \\
\hline Literatura paraguaya & 2 \\
\hline Novela histórica & 2 \\
\hline Raza de bronce & 2 \\
\hline Relaciones exteriores & 2 \\
\hline
\end{tabular}


Fuente: propia de la autora (2018).

\begin{tabular}{|l|l|}
\hline Repertorio americano & 2 \\
\hline Revolución & 2 \\
\hline Roa Bastos, Augusto 1917 & 2 \\
\hline Sandinismo & 2 \\
\hline Sociedad & 2 \\
\hline Trabajadoras & 2 \\
\hline
\end{tabular}

\section{Cuadro 13}

Áreas temáticas más representativas en los trabajos finales de graduación de la Maestría en Estudios Latinoamericanos, 1973-2015

\begin{tabular}{|l|c|}
\hline \multicolumn{1}{|c|}{ Temáticas } & Cantidad \\
\hline Identidad & 5 \\
\hline Indígenas & 4 \\
\hline Neoliberalismo & 4 \\
\hline Cultura & 4 \\
\hline Filosofía y ética & 4 \\
\hline Mujeres & 4 \\
\hline Educación secundaria & 2 \\
\hline Multiculturalismo & 2 \\
\hline Arte & 2 \\
\hline Migración & 2 \\
\hline Tecnología & 2 \\
\hline Globalización & 1 \\
\hline Farmacéutica & 1 \\
\hline Revistas & 1 \\
\hline Bibliotecas & 1 \\
\hline Gobernabilidad & 1 \\
\hline Contaminación & 1 \\
\hline Turismo rural & 1 \\
\hline Alfabetización & 1 \\
\hline Crecimiento América Latina & 1 \\
\hline Democracia & 1 \\
\hline
\end{tabular}

Fuente: propia de la autora (2018). 


\section{Cuadro 14}

Áreas temáticas de los trabajos finales de graduación de la Maestría en Derechos Humanos, 1973-2015

\begin{tabular}{|l|c|}
\hline \multicolumn{1}{|c|}{ Temáticas } & Cantidad \\
\hline Derechos Humanos & 12 \\
\hline Niñez & 10 \\
\hline Mujeres & 5 \\
\hline Indígenas & 4 \\
\hline Migración & 3 \\
\hline Cooperación & 2 \\
\hline Educación & 2 \\
\hline Prisiones & 2 \\
\hline Violencia intrafamiliar & 2 \\
\hline Adultos mayores & 1 \\
\hline Bullying & 1 \\
\hline Derechos sociales y económicos & 1 \\
\hline Democracia & 1 \\
\hline Docencia universitaria & 1 \\
\hline Género & 1 \\
\hline Genocidio & 1 \\
\hline Humanismo & 1 \\
\hline Libertad religiosa & 1 \\
\hline Medio ambiente & 1 \\
\hline Multiculturalismo & 1 \\
\hline Política civil & 1 \\
\hline Organizaciones sin fines de lucro & 1 \\
\hline Políticas migratorias & 1 \\
\hline Participación ciudadana & 1 \\
\hline Privados de libertad & 1 \\
\hline Racismo & 1 \\
\hline Refugiados & 1 \\
\hline Torturas & 1 \\
\hline Educación ambiental & 1 \\
\hline Tráfico de drogas & 1 \\
\hline Uniones de hecho & \\
\hline Pandillas & \\
\hline
\end{tabular}

Fuente: propia de la autora (2018). 
- Posgrados adscritos al Decanato de la Facultad de Filosofía y Letras

Existen en la Facultad de Filosofía y Letras dos programas de posgrado adscritos al Decanato, la Maestría en Estudios de Cultura Centroamericana en la que se han presentado 23 trabajos, el primero se presentó en 1999; y el Doctorado Interdisciplinario en Letras y Artes en América Central con 14, de los cuales se defendió el primer TFG en 2007. En el Cuadro 15 se detallan los temas, los cuales se caracterizan por su variedad.

\section{Cuadro 15}

Áreas temáticas de los trabajos finales de graduación de la Maestría en Estudios de Cultura Centroamericana y Doctorado Interdisciplinario en Letras y Artes en América Central, 1973-2015

\begin{tabular}{|l|c|}
\hline \multicolumn{1}{|c|}{ Temáticas } & Cantidad \\
\hline Análisis literario & 9 \\
\hline Literatura centroamericana & 4 \\
\hline Novela costarricense & 4 \\
\hline Iglesia católica & 3 \\
\hline Mujeres en la literatura & 3 \\
\hline Religión & 3 \\
\hline Bibliotecas infantiles, educativas y universitarias & 2 \\
\hline Condiciones sociales & 2 \\
\hline Género & 2 \\
\hline Poesía centroamericana & 2 \\
\hline Auditoría de la información & 1 \\
\hline
\end{tabular}

Fuente: propia de la autora (2018).

\section{ii. Países y regiones de Costa Rica más estudiados}

También es interesante conocer los países y regiones de Costa Rica más estudiados. No es sorpresa que nos estudiemos a nosotros mismos, pues 130 TFG tratan sobre Costa Rica, varios se enfocan en las provincias de Heredia, Limón, Guanacaste, San José y hay cuatro sobre la región de Pérez Zeledón. Resulta muy sugestivo encontrar 15 TFG sobre Nicaragua, 3 sobre El Salvador y Panamá, pero ninguno sobre Honduras ni Guatemala. (Ver Cuadro 16). 


\section{Cuadro 16}

Países y regiones más estudiados en los trabajos finales de graduación de la Facultad de Filosofía y Letras, 1973 - 2015

\begin{tabular}{|l|c|}
\hline \multicolumn{1}{|c|}{ País o región } & Cantidad \\
\hline Costa Rica & 130 \\
\hline América Latina & 24 \\
\hline Nicaragua & 15 \\
\hline América Central & 12 \\
\hline México & 7 \\
\hline América & 3 \\
\hline El Salvador & 3 \\
\hline Estados Unidos de América & 3 \\
\hline Panamá & 3 \\
\hline Colombia & 3 \\
\hline Chile & 2 \\
\hline
\end{tabular}

Fuente: propia de la autora (2018).

b. Fase 2: Análisis de los programas, proyectos y actividades académicas (PPAA) realizados en la Facultad de Filosofía y Letras de 1998 hasta 2015

En promedio, se ejecutan aproximadamente 65 PPAA por año, con un rango de variación amplio que puede ser de hasta 120 proyectos anuales; esta variación es tan grande debido a que los datos son escuetos e inconstantes, ya que como se mencionó en los antecedentes, en los inicios de la Facultad no se documentaba ni se describía esta información, y a veces solo consta en las actas del Consejo de Facultad los nombres de proyectos y de profesores a cargo de estos. Por lo tanto, es conveniente resaltar las características de los PPAA en los siguientes párrafos.

En los PPAA se invierte mucho esfuerzo y dinero; la gestión es muy importante y requiere de mucho tiempo porque incluye aprobar los proyectos idóneos, controlar el cumplimiento de los objetivos propuestos, dar seguimiento mediante la revisión de informes de avance anuales, la ejecución de sesiones de análisis integradas por expertos para evaluar los informes finales y 
las nuevas propuestas, etc. Aun así, se podría decir que los resultados de estos proyectos no tienen el seguimiento apropiado en el mediano y largo plazo.

Ejemplo de lo anterior, es que la disposición de las autoridades ha sido limitar la apertura o la continuación de cátedras y eliminar proyectos permanentes para promover los que generan conocimiento. Sin embargo, poco a poco, se establecieron nuevos portillos con procedimientos para formular etapas con cambios de nombre que son de seguimiento a proyectos antiguos.

Teniendo en cuenta este marco, los proyectos que se pudieron identificar fueron 1351, pero se determinó que 467 son continuación o etapas de proyectos que supuestamente ya se habían concluido y que en algunas ocasiones se convertían en cátedras permanentes, otros son actividades puntuales dirigidas a la gestión administrativa de la unidad académica (procesos de autoevaluación y acreditación de carreras), a la organización de eventos y los hay también para la gestión de las publicaciones periódicas de cada unidad, como se muestra a continuación:

- Producción académica: publicación de documentos, revistas, suplementos y boletines; 10 proyectos se ejecutan para publicar 12 publicaciones periódicas:

- Colección Prometeo, Hoja Filosófica y Revista Praxis

- Revista Ístmica

- Revista Repertorio Americano

- Revista Bibliotecas

- Revista Feminista Casa de la Mujer

- Revista Latinoamericana de Derechos Humanos

- Revista Letras

- Revista Temas de Nuestra América

- Siwó: Revista de Teología

- Suplemento Cultural

- Autoevaluación y acreditación de carreras.

- Creación de instancias que ofrecieran servicios especializados de información a la comunidad universitaria y herediana: se crearon centros de documentación y bibliotecas especializadas en las áreas de estudio de las unidades académicas de la Facultad que 
luego fueron la base para constituir la biblioteca de la Facultad, la cual inició también, como un proyecto. Asimismo, la Sala de Libros Antiguos (proyecto cerrado en 2015 y trasladada a la Biblioteca Joaquín García Monge) y la Biblioteca Infantil Miriam Álvarez Brenes. Esta última sigue vigente como proyecto de gestión académica de la Escuela de Bibliotecología, Documentación e Información.

- Educación continua a graduados, a maestros y profesores costarricenses.

- Divulgación del conocimiento.

- Realización de eventos académicos: foros, seminarios, congresos, simposios y otros.

- Cátedras: Hilda Chen Apuy, Emilia Prieto, Oscar Arnulfo Romero y Galdámez, Rigoberta Menchú Tum, Víctor Sanabria, Joaquín García Monge, Carmen Lyra y Rodrigo Carazo Odio.

Los PPAA se pueden enmarcar en cinco áreas del quehacer académico: docencia, investigación, extensión, producción y gestión académica; si incorporan varias áreas, como sabemos, se denominan proyectos integrados. La mayoría de los proyectos de la Facultad están incluidos en el área de investigación; también, hay una gran cantidad de proyectos integrados. La menor cantidad de proyectos se ubican en el área de docencia. En el Cuadro 17 se muestra la cantidad de proyectos de la Facultad de Filosofía y Letras distribuidos por año y se resaltan los que pertenecen al área de investigación.

\section{Cuadro 17}

Cantidad de PPAA de la Facultad de Filosofía y Letras, 1994-2016

\begin{tabular}{|c|c|c|}
\hline Años & Total de proyectos & $\begin{array}{c}\text { Proyectos área de } \\
\text { Investigación }\end{array}$ \\
\hline $1994-1995$ & 64 & 0 \\
\hline $1995-1996$ & 65 & 31 \\
\hline $1996-1997$ & 58 & 17 \\
\hline $1998-1999$ & 56 & 13 \\
\hline $1999-2000$ & 45 & 15 \\
\hline $2000-2001$ & 46 & 14 \\
\hline
\end{tabular}


Fuente: propia de la autora (2018).

\begin{tabular}{|c|c|c|}
\hline $2001-2002$ & 48 & 12 \\
\hline $2002-2003$ & 56 & 16 \\
\hline $2003-2004$ & 51 & 15 \\
\hline $2004-2005$ & 54 & 19 \\
\hline $2005-2006$ & 56 & 21 \\
\hline $2006-2007$ & 55 & 20 \\
\hline $2007-2008$ & 58 & 19 \\
\hline $2008-2009$ & 60 & 23 \\
\hline $2009-2010$ & 62 & 18 \\
\hline $2010-2011$ & 60 & 16 \\
\hline $2011-2012$ & 76 & 28 \\
\hline $2012-2013$ & 78 & 24 \\
\hline $2013-2014$ & 93 & 36 \\
\hline $2014-2015$ & 120 & 48 \\
\hline $2015-2016$ & 90 & 27 \\
\hline Total & 1351 & 432 \\
\hline
\end{tabular}

De los 1351 PPAA ejecutados en el periodo de estudio, se determinó que solo 299 son realmente representativos del quehacer y las fortalezas de las diferentes unidades académicas de la Facultad. Estos 299 PPAA también siguen el mismo comportamiento que los restantes, la gran mayoría (132) son de investigación, 98 son integrados, 36 son de extensión y 33 son de docencia. En el Cuadro 18 se muestra la distribución por áreas de los proyectos de la Facultad en los últimos cinco años: 


\section{Cuadro 18}

PPAA ordenados de acuerdo con las áreas de aplicación en la Facultad de Filosofía y Letras, 2011-2016*

\begin{tabular}{|l|c|c|c|c|c|c|c|}
\hline \multicolumn{1}{|c|}{ Áreas / Años } & $\mathbf{2 0 1 1}$ & $\mathbf{2 0 1 2}$ & $\mathbf{2 0 1 3}$ & $\mathbf{2 0 1 4}$ & $\mathbf{2 0 1 5}$ & $\mathbf{2 0 1 6}$ & Total \\
\hline Investigación & 55 & 56 & 46 & 49 & 48 & 37 & $\mathbf{2 9 1}$ \\
\hline Docencia & 39 & 49 & 40 & 40 & 38 & 26 & $\mathbf{2 3 2}$ \\
\hline Extensión & 24 & 34 & 35 & 35 & 34 & 27 & $\mathbf{1 8 9}$ \\
\hline
\end{tabular}

*No se incluyen los proyectos integrados

Fuente: propia de la autora (2018).

En el Cuadro 19 se muestra más específicamente la cantidad de PPAA por área, ordenados por unidad académica y por año, para que se puedan apreciar los cambios a lo largo de este quinquenio, las tendencias y con el fin de facilitar la revisión, el análisis de estos datos y la proyección a futuro.

\section{Cuadro 19}

PPAA ordenados de acuerdo con las áreas de aplicación en las unidades académicas de la Facultad de Filosofía y Letras, 2011-2016

\begin{tabular}{|c|c|c|c|c|c|c|c|c|c|c|c|c|c|c|c|c|c|c|}
\hline \multirow{2}{*}{$\begin{array}{c}\text { Unidad } \\
\text { académica }\end{array}$} & \multicolumn{3}{|c|}{2011} & \multicolumn{3}{|c|}{2012} & \multicolumn{3}{|c|}{2013} & \multicolumn{3}{|c|}{2014} & \multicolumn{3}{|c|}{2015} & \multicolumn{3}{|c|}{2016} \\
\hline & docencia & investigac & cextensión & docencia & investigac & extensión & docencia & investigac & extensión & docencia & investigac & extensión & $n$ docencia & investigac & cextensión & docencia & investigac & extensión \\
\hline Bibliotecología & 4 & 4 & 3 & 7 & 6 & 4 & 4 & 7 & 3 & 4 & 4 & 4 & 4 & 4 & 4 & 4 & 4 & 2 \\
\hline Filosofía & 3 & 7 & 4 & 3 & 6 & 2 & 2 & 4 & 2 & 4 & 9 & 4 & 4 & 10 & 4 & 2 & 8 & 3 \\
\hline Ecuménica & 7 & 8 & 1 & 7 & 8 & 3 & 5 & 6 & 3 & 5 & 6 & 5 & 5 & 5 & 3 & 5 & 6 & 3 \\
\hline Literatura & 4 & 15 & 6 & 13 & 18 & 12 & 12 & 16 & 13 & 10 & 16 & 13 & 12 & 17 & 13 & 8 & 14 & 10 \\
\hline lem & 17 & 14 & 7 & 11 & 11 & 6 & 11 & 8 & 7 & 8 & 8 & 5 & 7 & 6 & 5 & 2 & 1 & 4 \\
\hline Idela & 4 & 7 & 3 & 8 & 7 & 7 & 6 & 5 & 7 & 7 & 6 & 7 & 6 & 6 & 5 & 5 & 4 & 5 \\
\hline Total & 39 & 55 & 24 & 49 & 56 & 34 & 40 & 46 & 35 & 38 & 49 & 38 & 38 & 48 & 34 & 26 & 37 & 27 \\
\hline
\end{tabular}

Fuente: propia de la autora (2018).

Las áreas disciplinarias más estudiadas también se mantienen a lo largo de los años, estas se han constituido en una impronta de la Facultad en los últimos 19 años, las cuales se mencionan a continuación: identidades, diversidad, lenguas, lenguaje, cultura y política, mujer, género, violencia, sociedad, desarrollo, educación, políticas educativas e innovación, calidad de la 
educación, población y desarrollo humano, lógica y filosofía, estética, ética, espiritualidad, información y comunicación.

Al agrupar los proyectos por temáticas, llama la atención la gran cantidad de estos que son del área de ciencias sociales y de educación; los cuales suman más de 91, a lo largo de los años, habría que buscar una explicación válida ante esta situación, proponer cambios y la formulación de proyectos interdisciplinarios e inter-facultades.

Otros temas recurrentes y permanentes, desde los inicios de la Facultad, son: la elaboración de textos y antologías, la creación y edición de revistas y de libros, la organización de congresos, la gestión administrativa de las unidades académicas que incluye la elaboración de los planes de estudio, la creación y organización de bibliotecas y de servicios de información, la divulgación del quehacer.

El nivel de colaboración entre el personal académico se determinó con base en la cantidad de participantes por proyecto, las características profesionales, la participación de estudiantes y la tipología del proyecto, por ejemplo, interdisciplinario, multidisciplinario y transdisciplinario, las alianzas inter-unidades, inter-facultades, o con otras universidades del ámbito nacional e internacional. Como se nota en el Cuadro 20, al personal académico de la Facultad le gusta trabajar en forma individual.

El trabajo individual está muy arraigado; en 2011 las alianzas entre unidades de la Facultad se limitaban a cuatro proyectos: el Certamen UNA-Palabra, en el que participa la Escuela de Literatura y Ciencias del Lenguaje y la Escuela de Filosofía con el apoyo del Decanato; dos proyectos del Instituto de Estudios de la Mujer y la Biblioteca Electrónica de la FFL. 


\section{Cuadro 20}

\section{Cantidad de personas por proyecto. Facultad de Filosofía y Letras}

Fuente: propia de la autora (2018).

\begin{tabular}{|c|c|}
\hline $\begin{array}{c}\text { Cantidad de personas } \\
\text { por proyecto }\end{array}$ & $\begin{array}{c}\text { Cantidad de } \\
\text { proyectos }\end{array}$ \\
\hline 1 & 174 \\
\hline 2 & 61 \\
\hline 3 & 34 \\
\hline 4 & 17 \\
\hline 5 & 4 \\
\hline 6 & 5 \\
\hline 8 & 2 \\
\hline 9 & 1 \\
\hline 11 & 1 \\
\hline TOTAL & $\mathbf{2 9 9}$ \\
\hline
\end{tabular}

En los años 2013, 2014 y 2015 se establecieron alianzas entre los proyectos, se aprovecharon las oportunidades y se cumplió con las características deseables para los PPAA, de acuerdo con lo propuesto en el plan estratégico. En 2013 y 2014 se presentaron la mayor cantidad de proyectos vinculados:

1. Acompañamiento social participativo para el mejoramiento de la calidad de vida de las y los habitantes de Isla Venado y Lepanto, Instituto de Estudios de la Mujer (IEM), Escuela de Medicina Veterinaria, Centro de Investigación y Docencia en Educación (CIDE) y Facultad de Ciencias Exactas y Naturales.

2. Biblioteca electrónica de la Facultad de Filosofía y Letras de la Universidad Nacional, Escuela de Literatura y Ciencias del Lenguaje y Decanato.

3. Certamen UNA-Palabra: Premio Universidad Nacional (naturaleza anual), Premio Omar Dengo (naturaleza bienal), Escuela de Literatura y Ciencias del Lenguaje y Escuela de Filosofía.

4. Conocimiento, paz y gestión social, Escuela Ecuménica de Ciencias de la Religión, Escuela de Bibliotecología, Documentación e Información y Escuela de Filosofía. 
5. Construyendo espacios de diálogo intercultural desde el Colegio Humanístico de Coto, en torno a los derechos de pueblos indígenas, Escuela Ecuménica de Ciencias de la Religión, Escuela de Bibliotecología, Documentación e Información y Colegio Humanista de Coto.

6. Cosmovisión Malecu. Espiritualidad y prácticas ancestrales agropecuarias, nutrición y salud para el "buen vivir. Escuela Ecuménica de Ciencias de la Religión, Escuela de Ciencias Agrarias y Escuela de Medicina Veterinaria.

7. Educación para religar: reflexión y práctica creativa para la convivencia armoniosa. Escuela Ecuménica de Ciencias de la Religión y División de Educación Básica.

8. Epistemologías del sur: Red de pensamiento anticolonial respecto de lo educativo, lo migratorio y lo rural. Escuela de Sociología, División de Educología, IDESPO, Escuela de Filosofía, Sede Región Chorotega y Estudios Generales.

9. Innovaciones metodológicas participativas del Modelo de Acompañamiento Social Participativo con Perspectiva de Género aplicables a comunidades rurales y costeras. Instituto de Estudios de la Mujer y Facultad de Ciencias Exactas y Naturales.

10. Maestría Interuniversitaria en Bioética, Escuela de Filosofía. Escuela de Filosofía y Universidad de Costa Rica.

11. Medidas para la Inclusión y Equidad en Instituciones de Educación Superior en América Latina (MISEAL), proyecto financiado por el Gobierno de Alemania y ejecutado por el Instituto de Estudios de la Mujer (IEM).

12. Programa de Desarrollo Integral Comunitario Costero II (PDICC II), Instituto de Estudios de la Mujer y Facultad de Ciencias Exactas y Naturales.

13.XI Congreso de las Jornadas Andinas de Literatura latinoamericana (JALLA), Escuela de Literatura y Ciencias del Lenguaje, Decanato, y el Instituto de Estudios Latinoamericanos.

Los proyectos vinculados del 2015 disminuyeron nuevamente:

1. Biblioteca electrónica de la Facultad de Filosofía y Letras de la Universidad Nacional, Escuela de Literatura y Ciencias del Lenguaje y Decanato.

2. Certamen UNA-Palabra: Premio Universidad Nacional (naturaleza anual), Premio Omar Dengo (naturaleza bienal), Escuela de Literatura y Ciencias del Lenguaje y Escuela de Filosofía. 
3. Conocimiento, paz y gestión social, Escuela Ecuménica de Ciencias de la Religión, Escuela de Bibliotecología, Documentación e Información y Escuela de Filosofía.

4. Construyendo espacios de diálogo intercultural desde el Colegio Humanístico de Coto, en torno a los derechos de pueblos indígenas, Escuela Ecuménica de Ciencias de la Religión, Escuela de Bibliotecología, Documentación e Información y Colegio Humanista de Coto

5. Cosmovisión Malecu. Espiritualidad y prácticas ancestrales agropecuarias, nutrición y salud para el "buen vivir. Escuela Ecuménica de Ciencias de la Religión, Escuela de Ciencias Agrarias y Escuela de Medicina Veterinaria.

6. Educación para religar: reflexión y práctica creativa para la convivencia armoniosa. Escuela Ecuménica de Ciencias de la Religión y División de Educación Básica.

7. Epistemologías del sur: Red de pensamiento anticolonial respecto de lo educativo, lo migratorio y lo rural. Escuela de Sociología, División de Educología, IDESPO, Escuela de Filosofía, Sede Región Chorotega y Estudios Generales.

Los públicos meta de los PPAA son los profesionales, el sector universitario, estudiantes universitarios, estudiantes de I y II ciclo, adultos, organismos no gubernamentales, organizaciones sociales, población femenina, población indígena, Universidad Nacional, núcleo familiar, sociedad, niños y niñas, población migrante, estudiantes de preescolar, adolescentes y población con discapacidad.

Los resultados o productos son muy variados y dependen de la naturaleza del PPAA; los más representativos son la publicación de números de las revistas, la publicación de artículos, los informes técnicos, las ponencias ante eventos nacionales e internacionales, la elaboración de unidades didácticas, la creación y divulgación de bases de datos, la publicación de libros y de las memorias de eventos, congresos, simposios y conferencias, además, algunos proyectos ofrecen una propuesta de cursos optativos; tal como se muestra en el Cuadro 21. 


\section{Cuadro 21 \\ Resultados de los PPAA. Facultad de Filosofía y Letras}

Fuente: propia de la autora (2018).

\begin{tabular}{|l|c|}
\hline \multicolumn{1}{|c|}{ Tipo de resultado } & Cantidad \\
\hline Revista & 104 \\
\hline Artículo & 25 \\
\hline Informe técnico & 19 \\
\hline Ponencia & 14 \\
\hline Propuesta & 12 \\
\hline Unidad o guía didáctica & 11 \\
\hline Libros & 10 \\
\hline Memoria & 10 \\
\hline Base de datos & 10 \\
\hline Organización de actividades & 7 \\
\hline Diagnósticos & 6 \\
\hline Capítulo en libro & 4 \\
\hline Página web & 4 \\
\hline Vídeos o multimedios & 4 \\
\hline Compilación y edición & 3 \\
\hline Total & $\mathbf{2 4 3}$ \\
\hline
\end{tabular}

\section{A manera de conclusión y recomendación}

Esta investigación logró vislumbrar que, desde los orígenes de la Universidad Nacional en 1973, la investigación y las publicaciones acompañan el quehacer académico, la acción sustantiva y la práctica en la Facultad de Filosofía y Letras. Esta característica se fortalece en los años noventa con el surgimiento de cátedras especializadas sobre grandes pensadores costarricenses. Posteriormente, las cátedras perdieron vigencia, algunas ideas se fortalecieron con iniciativas a partir de las cuales se establecen líneas de pensamiento generadoras de conocimiento que se publica: identidades, diversidad, lengua, cultura y política, lenguas y lenguaje, mujer, género, violencia, sociedad, desarrollo, educación, políticas educativas e innovación, calidad de la educación, población y desarrollo humano, lógica y filosofía, estética, ética, espiritualidad, información y comunicación. 
También, se pudo constatar que no se dispone de estudios para determinar exactamente el aporte científico novedoso que se ha ofrecido desde esta casa de estudio al conocimiento científico y disciplinario, porque para eso es necesario realizar estudios bibliométricos, de citación de la documentación y determinar el impacto de estos proyectos en los diferentes escenarios para los que fueron planteados y el cumplimiento de los compromisos asumidos con el país.

EI SIDUNA debe ser garante de conservar y preservar el patrimonio documental memoria histórica de la Universidad. Se pudo constatar que muchos informes de los trabajos finales de graduación no están en las bibliotecas del SIDUNA, no se sabe que pasó posterior a su defensa, no se sabe si se publicaron, si se hicieron artículos o ponencias sobre esos temas o si fueron insumo de otras investigaciones. También, se pudo demostrar que en estas bibliotecas del SIDUNA se realiza muy poco control documental.

La gestión actual de la investigación se limita únicamente al control del cumplimiento formal de los tiempos, de los objetivos, productos, de los requisitos y de la presentación de informes para su aprobación. Luego de su aprobación no hay seguimiento a la publicación formal de los productos porque la publicación se da tres años o más después de terminado el proyecto y generalmente se publican fuera de la Editorial de la UNA (EUNA). Por esa razón, la Universidad pierde los derechos de autor de una gran cantidad de conocimiento generado con su presupuesto.

Se requiere una gestión de la documentación continua y de calidad para tener una visión completa de la situación y encauzar la investigación. Falta crear un sistema de gestión de la investigación y de la información académica que permita hacer correlaciones entre PPAA, TFG, repositorios, índices de citación y el avance científico para mapear el conocimiento y el aporte a la educación y a la sociedad.

Al no disponer de herramientas que faciliten el análisis minucioso, cualitativo y el seguimiento a la publicación editorial, hay muchas preguntas que se quedan sin respuestas, por ejemplo: 
¿todo ese trabajo realizado desde hace más de cuarenta y tres años está publicado y disponible?, ¿es usado en la docencia?, ¿corresponden las publicaciones con los objetivos propuestos en los proyectos?, ¿está justificada la inversión?

Sé por mi trabajo en el proyecto Scriptorium que no es así y por eso se recomienda elaborar un proyecto de Facultad para realizar ese estudio exhaustivo y una línea del tiempo que muestre esa realidad, su evolución y las tendencias a futuro.

En cuanto a los trabajos finales de graduación, se concluye que es muy poca la población estudiantil graduada de la Facultad en el nivel de licenciatura con respecto a la cantidad de estudiantes que ingresan todos los años: 869 personas graduadas de grado y posgrado es una cantidad muy limitada, especialmente si se considera que se han impartido 27 carreras a lo largo de 42 años. Llama la atención, también, la distribución de estos graduados en licenciatura que corresponde a 435 y posgrado con 434 , cifras muy similares y que representan otro hallazgo interesante: ¿será que es más fácil hacer un trabajo final de graduación en posgrado que en licenciatura? ¿será que la licenciatura ya no es tan importante en el mercado laboral?

En los 42 años de edad de la Facultad, hasta el 2015, hay una gran amplitud de temas estudiados que están vinculados a realidades nacionales de gran importancia, algunos corresponden con las grandes áreas de la Facultad, pero, hay muchos temas que no se reflejan ni en los planes de estudios, ni en el plan estratégico, temas que incluyen a instituciones, a organizaciones, a instancias y asuntos nacionales de gran importancia y de diverso carácter, estudiados ampliamente como parte de los TFG: humanistas, sociales, políticos, sobre aspectos éticos, morales, religiosos, espirituales. Son tantos que se sugiere su consulta en el formato digital, pero, a modo de ilustración, se mencionan algunos de estos del 2013:

1. Propuesta de proyección social del Comité de Bioética del Hospital Dr. Max Peralta de Cartago, a fin de aumentar la cobertura de atención en el pronóstico temprano y preventivo de la hiperplasia prostática y cáncer de próstata.

2. Proyecto Calero: una historia de militarización y xenofobia. 
3. Propuesta metodológica para la creación de repositorios institucionales, aplicada a cuatro instituciones públicas costarricenses.

4. Iglesia Católica y los Tinoco.

5. La migración nicaragüense a Costa Rica.

6. La menopausia: un proceso de crecimiento.

7. La posición de la Iglesia Católica y de los sectores populares en relación con la explotación minera de oro a cielo abierto en la zona norte de Costa Rica.

8. La psicología humanista en el pensamiento latinoamericano contemporáneo.

En algunas unidades académicas, los temas de los trabajos finales de graduación coinciden con las áreas de investigación propuestas, en sus grandes temas: lingüística, literatura, derecho, mujeres, género, sexo, educación, análisis y crítica literaria, teología, cultura, bibliotecas, ética, iglesia, violencia, feminismo, bioética, religión. Hay una gran cantidad de traducciones de obras de diversa naturaleza que ofrecen una amplia riqueza de material para utilizarlo en docencia. Pero, se deben revisar los planes de estudio y el plan estratégico para ampliarlos.

No se incluyeron en este estudio a 32 PPAA de vinculación externa inscritos en el Sistema de Información Académica (SIA) que es necesario estudiar con detenimiento en cuanto a los productos que se ofrecen a la sociedad costarricense y los beneficios económicos que generan. Los resultados de esta investigación deberían ser una herramienta de consulta para guiar al personal académico y al estudiantado en la selección de temas, problemas y áreas de investigación, de acuerdo con el avance del conocimiento en la Facultad, el estado de la cuestión, los procesos metodológicos utilizados, la innovación y la creatividad manifiesta en estas publicaciones.

En otra etapa de este estudio se debería constituir un observatorio del pensamiento académico para realizar análisis del discurso y los contenidos de las publicaciones con sello editorial y de los documentos sin sello editorial, para elaborar comparaciones más amplias en el nivel nacional e internacional y determinar el avance o no del conocimiento científico en las áreas 
disciplinarias estudiadas, también, para comprender la calidad, la complejidad y la novedad de esa producción.

\section{Referencias}

Facultad de Filosofía y Letras (2013). Plan estratégico Facultad de Filosofía y Letras 20132017. Heredia, C.R.: UNA.

\section{Nota de la Autora}

Aracelly Ugalde Víquez. Bibliotecóloga jubilada. Trabajó en la Escuela de Bibliotecología, Documentación e Información, Universidad Nacional, Costa Rica. Correo electrónico: mariarauga@gmail.com 
VIII. Apéndice

\section{Apéndice 1 \\ Listado de autores estudiados en los Trabajos Finales de Graduación de la Facultad de Filosofía y Letras, 1973-2015}

\begin{tabular}{|c|c|c|}
\hline Abel Pacheco & Edward Abbee & Jerzy Kosinskii \\
\hline Adolfo García Herrera & Eileen Barrett & Jesse Schwarts \\
\hline Alberto Moravia & Eleanor Whitney & Joaquín García Monge \\
\hline Aldous Leonard Huxley & Elisabeth Bumiller & Joaquín Pasos \\
\hline Alejandro Sieveking & Elizabeth Alan & Jorge Montero Madrigal \\
\hline Alfonso Chase Brenes & Ernesto Cardenal & José Marín Cañas \\
\hline Alfredo Cardona Pena & Ernesto Sábato & José Bustasio Rivera \\
\hline Allen Pence & Esteban Echeverría & José Enrique Rodó \\
\hline Amado Nervo & Faustino Víquez & José Lezama Lima \\
\hline Amando Céspedes Marín & Florence Rush & José Martí \\
\hline Andre Gide & Francis Carco & José Ortega y Gasset \\
\hline Anna Benson & Francisco Amighetti Ruiz & José Revueltas \\
\hline Augusto Roa Bastos & Francoise Sagan & Juan Luis Vives \\
\hline Bárbara Borntranger & Franz Kafka & Juan Manuel Sánchez \\
\hline Benito Lynch & Gabriel García Márquez & Barrantes \\
\hline Bernard Jensen & Gill Perry & Julieta Pinto González \\
\hline Bharti Kirchner & Gustavo Flaubert & León Gordis \\
\hline Carlos Fuentes & Henry Kissinger & Malcolm Lowry \\
\hline Carol Hodges & Hermann Hesse & Manuel Jiménez \\
\hline Chloe Sayer & Horacio Castellanos Moya & Manuel Zeno Gandia \\
\hline David Attenborough & Jacob Mey & Marco Retana Padilla \\
\hline David Crystal & Jacques Lacan & María Leal de Noguera \\
\hline David Herbert Lawrence & James E. Maragos & Mariano Azuela \\
\hline Dr. Mary Ann Block & James Younblood Henderson & Marie Battiste \\
\hline Dr. Morton D. Bogdonoff & Jean Shinoda & Mario Payeras \\
\hline Edna Copeland & Jean-Paul Sartre & Mary Cullinan \\
\hline
\end{tabular}




$\begin{array}{lll}\text { Mary Oliver } & \text { Richard Carpenter } & \text { Tomas Carrisquilla } \\ \text { Mary Pipher } & \text { Richard Johnson } & \text { Tomas Ocrohan } \\ \text { Max Glycine } & \text { Robert Jay Lifton } & \text { Valerie Love } \\ \text { Max Jiménez } & \text { Roberto Marín Guzmán } & \text { Vann Alton Daniels } \\ \text { Michel Paymar } & \text { Rodrigo Soto } & \text { Virginia Woolf } \\ \text { Miguel Fajardo Corea } & \text { Santiago Dabove } & \text { Walt Whitman } \\ \text { Nomi J. Waldman } & \text { Sarvepalli Radhakrishnan } & \text { Wilga Rivers } \\ \text { Par Laggerkvist } & \text { Sergio Ramírez } & \text { William Faulkner } \\ \text { Patrick Peyton } & \text { Shirley Jackson } & \text { Yolanda Colom } \\ \text { Quince Duncan } & \text { Siany Gordon Spence } & \text { Yolanda Oreamuno } \\ \text { Raymond Bruman } & \text { Sigmund Freud } & \text { Zeno Isaacs } \\ \text { Rebecca L. Oxford } & \text { Simone de Beauvoir } & \\ \text { Ricardo Fernández Guardia } & \text { Thomas Partner } & \end{array}$

Fuente: El listado es propio de la autora (2018). 